\title{
TESTS FOR THE ADULTERATION OF HUMAN MILK
}

\author{
BY \\ R. A. MILLER and R. W. B. ELLIS \\ From the Royal Hospital for Sick Children, Edinburgh, and the Department of Child Life and Health, University of \\ Edinburgh
}

(RECEIVED FOR PUBLICATION JANUARY 26, 1953)

The necessity for testing human milk destined for milk banks in order to eliminate specimens which have been adulterated with water or cow's milk has been widely recognized since the introduction of such banks in 1910 (Mackintosh, 1947). In some centres, however, no tests for adulteration seem to be used, in spite of the fact that the mothers providing milk for these banks are not supervised between the time they express the milk and deliver it to the milk bank or milk bank official.

Various tests have been used to detect adulteration, and there is to this day no agreement on which are most reliable. The selection of tests in the past has depended partly on the efficiency of a test but also on other factors such as the speed and ease with which a test can be performed, the simplicity of the apparatus, the ease with which reagents and sera can be obtained, and financial considerations. It would appear therefore that the ideal test or combination of tests used in the detection of adulteration of human milk with water or cow's milk should be quick and easy to perform and preferably should not involve complicated or expensive apparatus. The test must be reliable and able to detect minor degrees of adulteration. With these criteria in mind the many tests recommended for the detection of adulteration have been reviewed and those which best fulfil the conditions selected for discussion. In addition an investigation has been made into the freezing point of women's milk; the value of assessing the freezing point or the electrical conductivity of women's milk for the detection of adulteration of the milk has been explored.

\section{Review of the Literature}

Since last century many methods of detecting the adulteration of women's milk have been devised. Usually one test appears no better than another and the tests are neither sufficiently sensitive nor reliable. This is probably because the physical and chemical properties of milk vary from case to case and even in a given individual.
At least six simple tests have been advocated for the detection of water added to women's milk. Two are based on the determination of a physical property of the milk, and three depend on its chemical composition. The sixth is a combination of the two tests, one involving a physical property and one a chemical property of milk. Of these tests based on physical properties, the first necessitates the estimation of the refractive index of the milk specimen in question. The interpretation of the results must be made cautiously because they vary for genuine milk, particularly if the sugar or solids-not-fat contained in the milk alter either under physiological conditions or on account of disease. Gnosspelius (1940) when criticizing the test says that it is necessary to obtain a control sample of milk reliably obtained from the woman under test. The refractive index of both the given milk sample and the control sample is made and the results compared. By this method $10 \%$ or more of added water can be detected (Kappeller and Gottfried, 1920; Zaribnicky, 1942). In the dairy world the refractive index is not a reliable test for detecting adulteration, and it therefore appears that the results of the refractometric test are unlikely to be reliable for the detection of adulterated human milk. The second test involves measurements of the specific gravity of the milk specimen. This is an unsatisfactory test because it is only suitable for detecting gross adulteration.

Of the three tests based on the chemical composition of milk, the first involves the estimation of its chloride content. From the results it is usually possible to detect large amounts of added water. The test, however, is not reliable or of practical value (Miller, 1949). In the second test both chloride and lactose content of the specimen are determined. From the results the chloride-lactose ratio is calculated. In the case of genuine human milk it is $0.44 \pm 0.015$. The ratio may be greater and approximate to that of cow's milk, $2 \cdot 23 \pm 0 \cdot 082$, if the milk is from women in the first month of lactation or from women with inadequate lactation. It is highly 
unlikely, however, that such women would be donors to a milk bank (Keller and Mai, 1930). Milk adulterated with large amounts of water has a chloridelactose ratio less than 0.425 . The third test is dependent on the relatively high lactose and low albumin content of the milk to detect adulteration. From the tint which originates by a reduction of a copper salt solution by the lactose in the milk-serum and by the amount of oxide of iron necessary for a quantitative precipitation of albumin, Edelstein (1921) was able to ascertain whether or not the human milk had been mixed with 20 to $30 \%$ or more of water. This test, however, is not reliable.

The final test for the detection of added water involves the estimation of the specific gravity of the milk and its fat content. The data is then used to give a point on the chart devised by Ström (1939) or for a formula. From the position of the point on the chart or from the result obtained by a special formula it is possible to detect $30 \%$ or more of water added to the specimen.

It has been shown that it is difficult to detect milk samples to which water has been added. Probably the least unsatisfactory method is to measure the refractive index of the milk. Other methods which may be adopted involve the estimation of the specific gravity and the percentage of milk fat, or the chloride and lactose content of milk, or the lactose and albumin content of milk.

Many quick and easy tests for the detection of human milk adulterated with cow's milk are available. These tests have been placed in one of four groups for the purpose of description and discussion. Group 1 includes tests dependent on a physical property of the milk, Group 2 includes those tests which necessitate investigation of one or two constituents of the milk, tests in Group 3 require the estimation of the hydrogen ion concentration of the milk in question, while those in Group 4 entail a biological investigation. In Group 1 (physical properties) the ultra-violet light test has been widely used because it is possible to detect the addition of small amounts of cow's milk in this way. Human milk normally gives a blue and cow's milk a yellow luminescence. Unfortunately both false positive and false negative results are sometimes obtained by this method (Griebel, 1937; Kayser, 1938; Smith, 1942). Another test, involving the estimation of the refractive index of the suspected milk detects an adulteration with cow's milk of $20 \%$ or more provided a reliable sample of milk from the woman who is being investigated can be similarly tested and the two results compared (Kappeller and Gottfried, 1920; Zaribnicky, 1942).

The second group of tests necessitates either the qualitative or quantitative analysis of some constituent of the milk. In one test both the chloride and lactose are estimated (Keller and Mai, 1930; Moruzzi and Tanzi, 1931). From the results the chloride-lactose ratio is calculated; when the ratio exceeds 0.455 adulteration must be suspected. Twenty-five per cent. or more of cow's milk added to the sample is usually detected. Edelstein in 1921 introduced the lactose-albumin test which detects $20 \%$ or more of added cow's milk, but the author states that the results are unreliable. Umikoff in 1896 devised a method of detecting adulterated milk by adding ammonia to the sample and heating it to $60=C$. The colour of the heated mixture depended on the amount of lactose and citric acid present in the milk. In this way the presence of $20 \%$ or more of cow's milk could be detected. The end-point of this test is sometimes indefinite and difficult to interpret. The xanthine-oxidase test (Rodkey and Ball, 1946) is a simple test and is based on the fact that cow's milk is rich in the enzyme, xanthine, while human milk has so little xanthine it is undetected by this test. Milk adulterated with $10^{\circ}$ o of cow's milk or more can be detected. Unfortunately the test is useless if the milk is boiled because the enzyme, xanthine oxidase, is destroyed.

In the third group of tests the hydrogen ion concentration of the milk under test is estimated by the addition of some indicator such as neutral red (Moro, 1912) nile-blue sulphate (Bauer, 1913; Solé, 1935) or haematoxylin (Smith, 1942). By these methods 20 to $30 \%$ or more of added cow's milk can be detected. On some occasions, however, the interpretation of the colour reaction can be extremely difficult, while in others fallacious results may be obtained because the milk has been kept too long before testing. Soxhlet-Henkel's test for titratable acidity results which are more reliable and informative (Eldson and Walker, 1942). By their method acidity over 2 degrees indicates adulteration with cow's milk provided the test is made on fresh milk (Kayser, 1935).

In the fourth group, tests involving the use of the anaphylactic response have proved impractical and the technical procedure of the complement fixation test far too complicated (Gnosspelius, 1940). The precipitation test, however, using specially prepared sera is very sensitive and reliable and can be quickly and easily performed. By means of this test $2 \%$ or more of added cow's milk can be detected. There is little doubt that this is the ideal test for the investigation of adulteration of human milk with animal's milk (Kayser, 1938; Urbach, 1938; Brakhage and Raettig, 1940; Gnosspelius, 1940). Unfortunately, at the present time the sera required for this test are 
not available in Great Britain. Once they can be obtained it is unlikely that there will be any necessity to resort to any alternative procedure. Until then, however, it will be necessary to select at least one of the tests already mentioned for the detection of adulteration of human milk with cow's milk. It should be remembered, however, that no test except the precipitation test gives conclusive evidence of the type of animal milk which has been added to the human milk.

\section{Investigation of Freezing Point of Women's Milk}

Methods. A few comments about the apparatus and method for measuring the freezing point, electrical conductivity and chloride content of milk are necessary.

The cryoscope devised by Hortvet in 1921 is the generally accepted apparatus for determining the freezing point of cow's milk (Lyons and O'Shea, 1950). This apparatus was used for measuring the freezing point of women's milk. The method of standardization of the thermometers was that suggested by Aschaffenburg and King (1951) and the apparatus was operated as described by the Association of Official Agricultural Chemists (1930). A more rigid method of stirring the milk under test, tapping the thermometer and reading the depression of freezing point recommended by Aschaffenburg and King (1951) was adopted. Throughout the investigation, which lasted from April to August, 1952, the temperature of the room was noted to vary by $9^{\circ} \mathrm{C}$. The freezing point of each specimen was recorded in degrees Centigrade. In no case was any allowance made for this variation or for the degree of acidity of the milk.

The electrical conductivity was measured with a commercial Wheatstone bridge; a U-shaped cell for holding the milk to be tested and two platinum electrodes were used in the circuit. The specific conductivity was calculated from the resistance for a given sample of milk and the cell constant for the apparatus. The results were all corrected to give the specific conductivity of the milk at $18^{\circ} \mathrm{C}$. Full details of this type of investigation are given by Kermack and Miller (1951).

The chloride content of the milk was determined by the method described by Patterson (1928). Ten millilitres instead of $2 \mathrm{ml}$. milk were used for the titration because this gave more accurate results. The chloride content of the milk was calculated in terms of milligrams of sodium chloride per $100 \mathrm{ml}$. of milk.

Material. The investigation was made on milk samples obtained from 215 women who were apparently healthy, at some stage of lactation between the fourth day and twenty-fourth week.
One hundred and seventy of these women provided one sample of milk each. Twenty-six women supplied one sample from each breast and each of these women gave her two samples on the same day. Nineteen women gave two samples each but these were taken at different stages of lactation. Thus a total of 260 samples of milk were obtained and examined. Almost invariably the milk was expressed into a specially prepared screw-capped jar after the baby had been fed. The size of each sample was approximately $30 \mathrm{ml}$. and it was stored in a refrigerator until tested. The test was performed within 24 hours of the time the milk was expressed. The freezing point was determined for each of the 260 samples and the electrical conductivity and chloride estimations were made on 245 samples.

TO SHOW THE PERCENTAGE OF WOMEN WHO HANE MLK WITH A GIVEN DEPRESSION OF FREEZING POINT $(\Delta)$

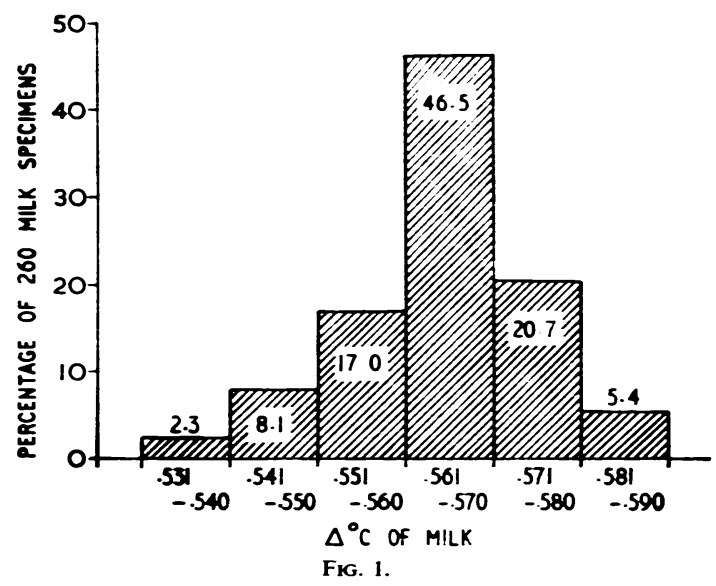

Results. The results of the investigation into the freezing point of human milk are given in Fig. 1. In this figure the percentage of the 260 samples of milk with a depression of freezing point between 0.531 and $0 \cdot 540,0 \cdot 541$ and $0 \cdot 550,0 \cdot 551$ and $0 \cdot 560,0 \cdot 561$ and $0 \cdot 570,0 \cdot 571$ and 0.580 and 0.581 and $0.590^{\circ} \mathrm{C}$. has been adopted. The greatest number of results in any one group is $46.6 \%$ in the group ranging from $0 \cdot 561$ to $0 \cdot 570$, while the smallest number of results, $2.3 \%$ is in the group ranging from 0.531 to $0.540^{\circ} \mathrm{C}$. The minimum and maximum depressions of freezing point obtained in this investigation are $0.531^{\circ} \mathrm{C}$. and $0 \cdot 586^{\circ} \mathrm{C}$. respectively and the mean depression of the freezing point for the 260 observations is $0.564^{c} \mathrm{C}$. These figures are of importance when using this test to detect the addition of water to milk. 
TABLE 1

AVERAGE DEPRESSION OF FREEZING POINT OF MILK $(\triangle)$ TAKEN FROM WOMEN AT DIFFERENT STAGES OF LACTATION

\begin{tabular}{|c|c|c|c|c|c|c|c|c|c|c|c|}
\hline & & & \multicolumn{9}{|c|}{ Week of Lactation } \\
\hline 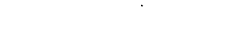 & & & 1 & 2 & 3 & 4 & $5-3$ & $9-12$ & $13-16$ & $17-20$ & $21-24$ \\
\hline Average $\Delta=C . \quad \cdots$ & . & $\ldots$ & 0.563 & $0 \cdot 566$ & $0 \cdot 570$ & 0.563 & 0.563 & $0 \cdot 563$ & $0 \cdot 569$ & $0 \cdot 567$ & 0.566 \\
\hline No. of samples tested & . & . & 90 & 85 & 12 & 4 & 36 & 16 & 6 & 6 & 5 \\
\hline No. of women tested & $\ldots$ & .. & 76 & 74 & 12 & 4 & 34 & 15 & 6 & 6 & 6 \\
\hline
\end{tabular}

If the freezing point test is to be used to detect adulterated milk it is important to know whether the mean depression of the freezing point varies with the stage of lactation. Table 1 has been constructed to elucidate this point. In this table are the mean depressions of freezing point for milk samples taken from women in each of the following periods of lactation: the second, third, fourth, fifth to eighth, ninth to twelfth, thirteenth to sixteenth, seventeenth to twentieth and twenty-first to twenty-fourth weeks after childbirth. Set out with each mean are both the number of observations and the number of women tested. The means do not differ markedly from the mean of $0.564^{\circ} \mathrm{C}$. for the entire investigation. In the two groups whose means differ most from the common mean the values have been based on relatively few observations and are, therefore, more liable to deviation. It appears, therefore, that there is no tendency for the depression of freezing point to alter significantly as lactation advances from the first to the twenty-fourth week after childbirth.

TABLE 2

COMPARISON OF DEPRESSION OF FREEZING POINTS $(\triangle)$ OBTAINED FOR SAMPLES OF MILK TAKEN FROM THE $\%$ TWO BREASTS

\begin{tabular}{|c|c|c|}
\hline \multirow[b]{2}{*}{ Case No. } & \multicolumn{2}{|c|}{$\Delta^{\circ}$ C. Milk } \\
\hline & Right Breast & Left Breast \\
\hline $\begin{array}{r}1 \\
2 \\
3 \\
4 \\
5 \\
6 \\
7 \\
8 \\
9 \\
10 \\
11 \\
12 \\
13 \\
14 \\
15 \\
16 \\
17 \\
18 \\
19 \\
20 \\
21 \\
22 \\
23 \\
24 \\
25 \\
26\end{array}$ & $\begin{array}{l}0 \cdot 550 \\
0 \cdot 540 \\
0 \cdot 541 \\
0 \cdot 550 \\
0 \cdot 543 \\
0 \cdot 549 \\
0 \cdot 550 \\
0 \cdot 560 \\
0 \cdot 555 \\
0 \cdot 553 \\
0 \cdot 550 \\
0 \cdot 555 \\
0 \cdot 568 \\
0 \cdot 552 \\
0 \cdot 549 \\
0 \cdot 550 \\
0 \cdot 540 \\
0 \cdot 530 \\
0 \cdot 562 \\
0 \cdot 542 \\
0 \cdot 554 \\
0 \cdot 560 \\
0 \cdot 549 \\
0 \cdot 561 \\
0 \cdot 549 \\
0 \cdot 530\end{array}$ & $\begin{array}{l}0 \cdot 560 \\
0 \cdot 540 \\
0 \cdot 549 \\
0 \cdot 551 \\
0 \cdot 543 \\
0 \cdot 544 \\
0 \cdot 550 \\
0 \cdot 560 \\
0 \cdot 551 \\
0 \cdot 550 \\
0 \cdot 560 \\
0 \cdot 558 \\
0 \cdot 560 \\
0 \cdot 560 \\
0 \cdot 543 \\
0 \cdot 551 \\
0 \cdot 548 \\
0 \cdot 539 \\
0 \cdot 552 \\
0 \cdot 550 \\
0 \cdot 550 \\
0 \cdot 560 \\
0 \cdot 551 \\
0 \cdot 555 \\
0 \cdot 545 \\
0 \cdot 530\end{array}$ \\
\hline
\end{tabular}

In two further investigations the freezing point of milk samples taken first from the two breasts was compared, and second a comparison was made between two samples obtained from the same woman at different stages of lactation. Two series of women were investigated; the first comprised 26 women each of whom expressed milk from both breasts keeping each specimen separate. The freezing point of the milk from each breast was determined and the results recorded in Table 2. A difference between the two results for a given woman was generally noted. It was usually no greater than $0.004^{\circ} \mathrm{C}$. which could be due to either a slight difference in the composition of the two samples or to experimental error. In 11 cases, however, the difference exceeded $0.004^{\circ} \mathrm{C}$. an amount which could not entirely be accounted for by experimental error. Thus some variation in the composition of the two samples would seem to be the most likely explanation for the difference in the freezing points of milk from the same woman.

A series of 19 women were selected for the investigation into the effect of state of lactation upon the freezing point of their milk. These women provided two samples of milk each taken at a different period of lactation. The freezing points of the samples are recorded in Table 3 where it can be seen that the

TABLE 3

COMPARISON OF DEPRESSION OF FREEZING POINTS $(\cdot)$ FOR TWO SAMPLES OF MILK OBTAINED FROM THE SAME WOMAN AT DIFFERENT STAGES OF LACTATION

\begin{tabular}{|c|c|c|c|c|}
\hline Case No. & $\begin{array}{l}\text { Week of } \\
\text { Lactation }\end{array}$ & $\therefore=C$. & $\begin{array}{l}\text { Week of } \\
\text { Lactation }\end{array}$ & $\therefore c$. \\
\hline $\begin{array}{r}1 \\
2 \\
3 \\
4 \\
5 \\
6 \\
7 \\
8 \\
9 \\
10 \\
11 \\
12 \\
13 \\
14 \\
15 \\
16 \\
17 \\
18 \\
19\end{array}$ & $\begin{array}{r}1 \\
1 \\
1 \\
1 \\
1 \\
1 \\
1 \\
1 \\
1 \\
1 \\
2 \\
2 \\
2 \\
2 \\
3 \\
3 \\
3 \\
6 \\
10\end{array}$ & $\begin{array}{l}0 \cdot 565 \\
0 \cdot 554 \\
0 \cdot 565 \\
0 \cdot 561 \\
0 \cdot 549 \\
0 \cdot 543 \\
0 \cdot 563 \\
0 \cdot 565 \\
0 \cdot 561 \\
0 \cdot 566 \\
0 \cdot 564 \\
0 \cdot 585 \\
0 \cdot 565 \\
0 \cdot 575 \\
0 \cdot 563 \\
0 \cdot 555 \\
0 \cdot 565 \\
0 \cdot 563 \\
0 \cdot 575\end{array}$ & $\begin{array}{r}\frac{2}{2} \\
\frac{2}{2} \\
\frac{2}{2} \\
\frac{2}{2} \\
\frac{2}{2} \\
6 \\
6 \\
2 \\
\frac{3}{3} \\
7 \\
6 \\
7 \\
13 \\
10 \\
17\end{array}$ & $\begin{array}{l}0 \cdot 582 \\
0 \cdot 565 \\
0 \cdot 575 \\
0 \cdot 565 \\
0 \cdot 576 \\
0 \cdot 555 \\
0 \cdot 562 \\
0 \cdot 567 \\
0 \cdot 564 \\
0 \cdot 555 \\
0 \cdot 565 \\
0 \cdot 570 \\
0 \cdot 554 \\
0 \cdot 565 \\
0 \cdot 565 \\
0 \cdot 550 \\
0 \cdot 5744 \\
0 \cdot 556 \\
0 \cdot 572\end{array}$ \\
\hline
\end{tabular}




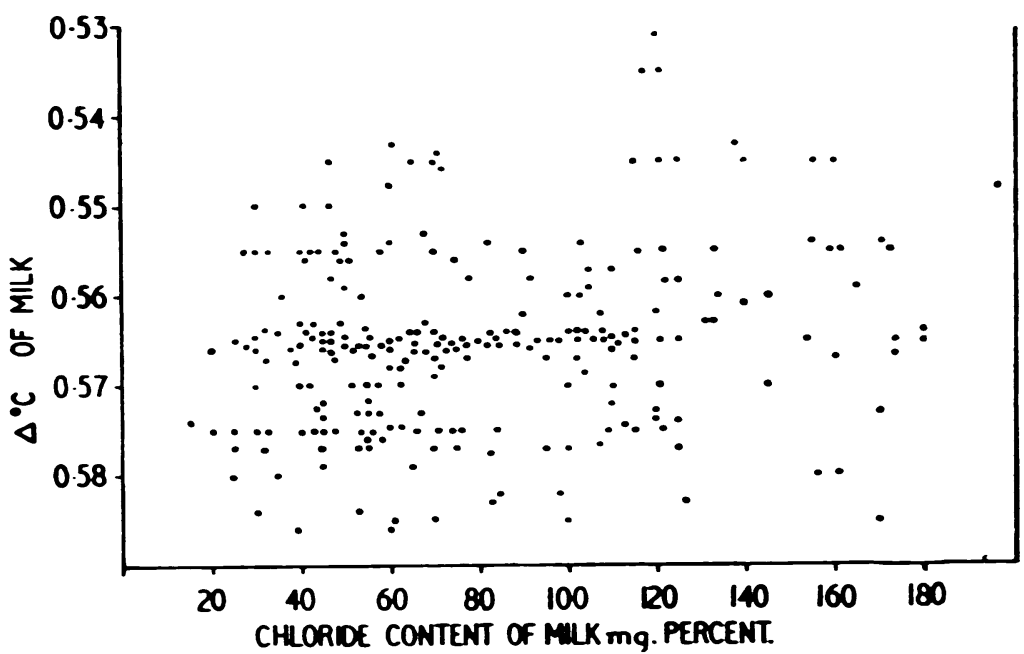

Fig. 2.

value obtained for the second sample may be either greater or smaller than that obtained for the first sample. The difference between the freezing points for the two samples from a given woman in some cases amounts to at least $0.005^{\circ} \mathrm{C}$., an amount which can be explained by a change in the composition of the milk.

An investigation was made into the freezing point, chloride content and electrical conductivity of samples of human milk to determine whether any relationship existed between the freezing point and the other physico-chemical properties. Two hundred and forty-five milk samples were examined, on each of which the freezing point, chloride content and electrical conductivity were estimated. The results are summarized in Tables 4 and 5 where it is apparent that the average freezing point of milk samples with a low chloride content does not differ appreciably from that for milk samples with a high chloride content. The scatter graph (Fig. 2) shows that there is no relationship between individual values and depression of freezing point. From Table 5 it can also be seen that the average freezing point for milk of a low electrical conductivity does not differ appreciably from that for milk of a high electrical conductivity. The scatter graph (Fig. 3) shows that there is no relationship between individual

Fig. 3. electrical conductivity values and the depression of the freezing point. It is, therefore, apparent that there is no relationship between the depression of freezing point of milk and its chloride content or its electrical conductivity.

Freezing Point Test. The addition of water to cow's milk can be detected quickly and easily by determining the freezing point of the given sample. If water has been added the freezing point is higher than that of unadulterated milk. This result can be used to estimate the

TABLE 4

AVERAGE VALUE FOR THE DEPRESSION OF FREEZING POINT $(\triangle)$ FOR MILK OF DIFFERENT CHLORIDE CONTENT

\begin{tabular}{|c|c|c|}
\hline $\begin{array}{c}\text { Chloride Content } \\
\text { (m\& \%) }\end{array}$ & No. of Specimens & Average $\Delta^{\circ} \mathbf{C}$. \\
\hline $\begin{array}{c}1-50 \\
51-100 \\
101-150 \\
151-200\end{array}$ & $\begin{array}{r}64 \\
105 \\
58 \\
18\end{array}$ & $\begin{array}{l}0 \cdot 563 \\
0 \cdot 567 \\
0 \cdot 564 \\
0 \cdot 562\end{array}$ \\
\hline
\end{tabular}

TABLE 5

AVERAGE VALUE FOR THE DEPRESSION OF FREEZING POINT $(\triangle)$ FOR MILK OF DIFFERENT ELECTRICAI

\begin{tabular}{ccc}
\multicolumn{3}{c}{ CONDUCTIVITY } \\
$\begin{array}{ccc}\text { Electrical Conductivity } \\
\left(10^{-5} \text { ohm }{ }^{-1} \text { cm. }-1\right)\end{array}$ & Na of Specimens & Average $\Delta \cdot C$. \\
\hline $151-200$ & 85 & $0 \cdot 566$ \\
$201-250$ & 94 & $0 \cdot 566$ \\
$251-300$ & 53 & $0 \cdot 562$ \\
$301-350$ & 13 & $0 \cdot 563$ \\
\hline
\end{tabular}

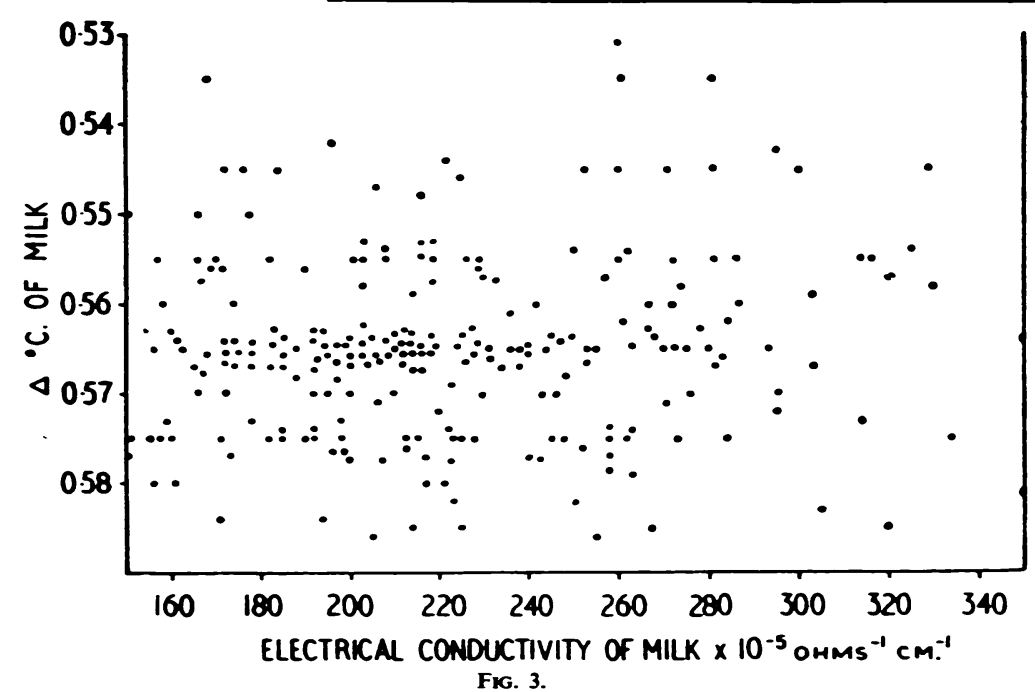


approximate amount of water added to the specimen by means of the formula

$$
W=\frac{100\left(T-T^{\prime}\right) \%}{T}
$$

recommended by the American Association of Official Agricultural Chemists where $W$ is the amount of water added, $T^{\prime}$ is the freezing point depression of the sample, and $T$ is the freezing point depression of genuine milk (or an average for genuine milk), and though the results obtained by the formula are a slight over-estimation of the percentage of added water, they are sufficiently accurate for practical purposes (Elsdon and Walker, 1942).

A series of observations were made on human milk, to which had been added varying amounts of water, to determine whether the above formula was of value in the estimation of adulteration of women's milk with water. A quantity of women's milk was divided into four parts, and each part was adulterated with $3 \cdot 3,16 \cdot 6,33 \cdot 3$ and $66 \cdot 6 \%$ of water respectively. The freezing point of each specimen $(x)$ was estimated by the method already described and recorded in Fig. 4. The theoretical freezing point $(\cdot)$ of each specimen was calculated from the formula and lay on a straight line connecting the depression of freezing point of unadulterated milk with the freezing point of water (see Fig. 4). The comparison of the experimental-theoretical values for a given dilution of milk showed that they were either the same or the experimental value was slightly higher than the theoretical value. It was also apparent from Fig. 4 that if the amount of added water were calculated from the theoretical value it might be as much as $2 \%$ in excess of the correct amount. This difference is not of practical importance. Therefore, the suggested formula, based on the principle that the raising of the freezing point of milk by the addition of water is proportional to the amount of added water, is of practical value in calculating the degree of adulteration of women's milk. Similar results have been obtained for dilution of cow's milk and have been explained by Elsdon and Walker (1942).

The sensitivity of the freezing point test is partly dependent upon the range of freezing point depression for genuine human milk; this range is 0.531 to $0.586^{-}$C. Since the addition of water to milk raises the freezing point, the percentage of water which must be added to milk with the lowest freezing point, $0.586^{\circ} \mathrm{C}$., to raise it above the highest freezing point, obtained for normal unadulterated milk is a measure of the test's sensitivity. This value is $\mathbf{9 . 7 5 \%}$. Therefore, the freezing point test will detect $10 \%$ or more of water added to women's milk. If the test is used for milk which has a higher freezing point than $0.586^{\circ} \mathrm{C}$. less than $10 \%$ adulteration can be detected.

\section{The Electrical Conductivity Test}

The electrical conductivity test for detecting adulteration of women's milk has not hitherto been described. The measurement of electrical conductivity is simple (Kermack and Miller, 1951) but the interpretation of the results, together with the

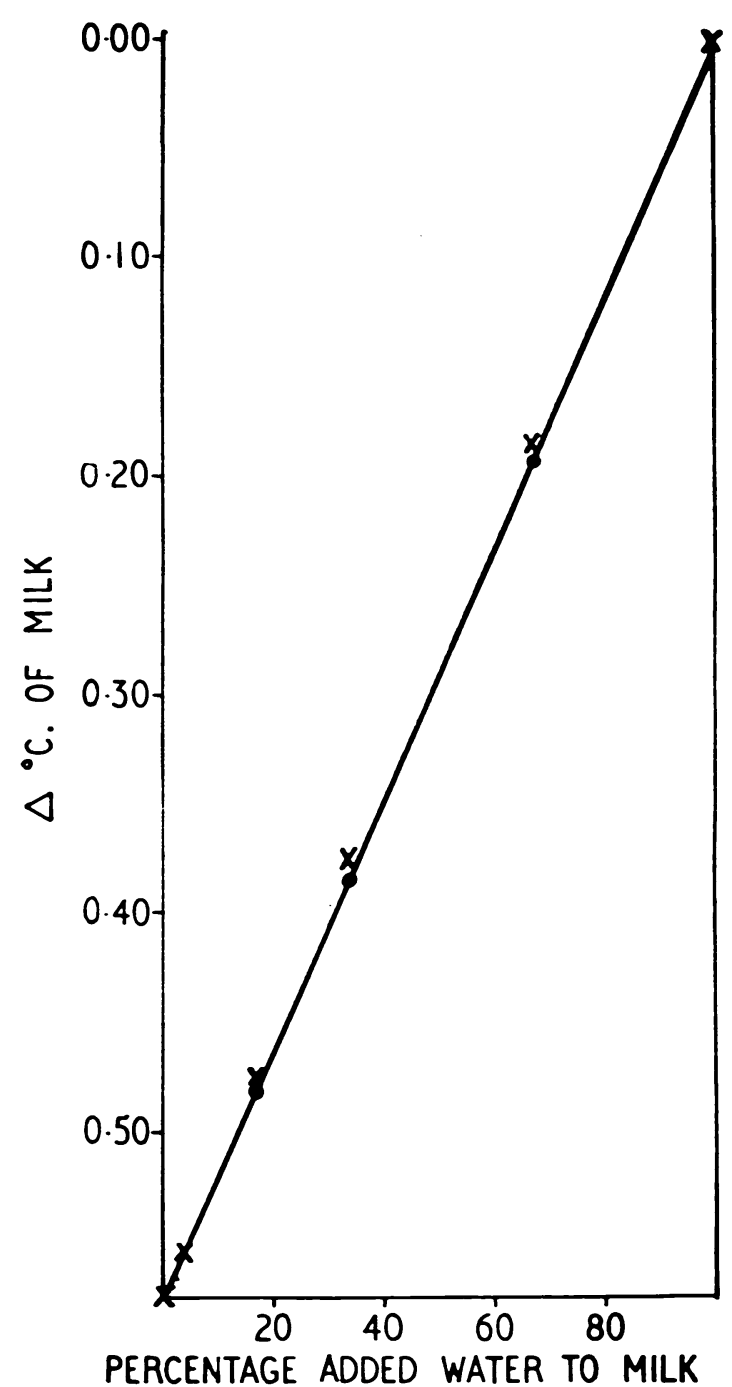

Fig. 4.-To show the changes in the depression of freering point of milk which occurs when it was watered.

$(X)$ represents the depression of freezing point of mixtures based on practical observations while $(\cdot)$ represents the depression of freezing point based on theoretical calculations. 
sensitivity of the test and its fallacies require careful consideration. It is, therefore, necessary to consider the test as a method for the detection of both added water and added cow's milk. The addition of water to human milk reduces its electrical conductivity. The reduction is almost proportional to the amount of added water. Usually the experimental value for a given dilution of milk is $1-9 \%$ less than the theoretical electrical conductivity value (Fig. 5). The difference between the measured and the theoretical values

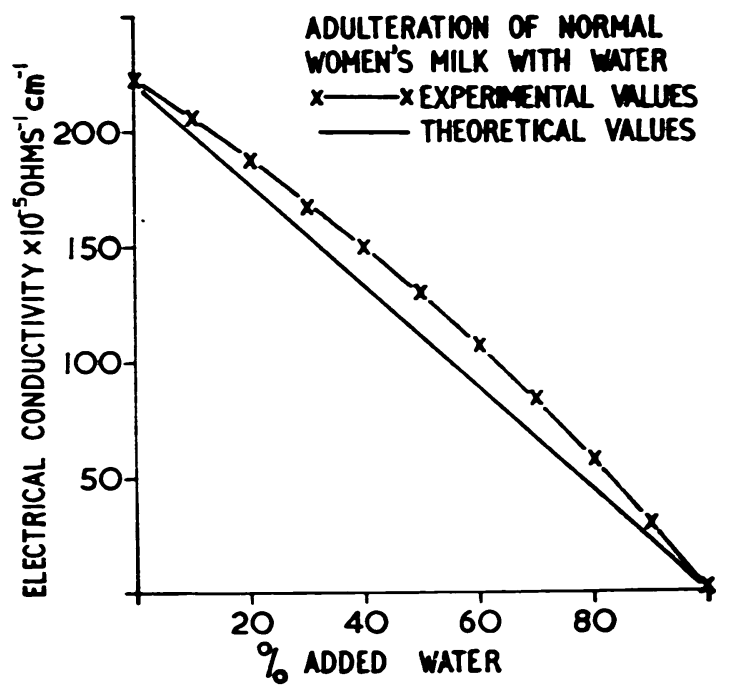

FIG. 5.

is partly due to the change in the viscosity of the milk and to the increased dissociation of certain electrolytes in the diluted milk.

The amount of added water which can be detected by the electrical conductivity test depends on the initial electrical conductivity value of the milk. This ranges from 210 to $150 \times 10^{-5} \mathrm{ohm}^{-1} \mathrm{~cm} .^{-1}$ for women lactating adequately in the second to fifth month of lactation (Miller, 1951). Since the values fall when water is added, milk with the highest electrical conductivity value, $210 \times 10^{-5} \mathrm{ohm}^{-1} \mathrm{~cm}^{-1}$, will require the maximum amount of water $(33 \%)$ to lower its conductivity below the minimum value of $150 \times 10^{-3}$ $\mathrm{ohm}^{-1} \mathrm{~cm} .^{-1}$. Therefore it follows that by means of the test at least $33 \%$ added water can be detected in milk from mothers with adequate lactation in the second to fifth month of lactation. Occasionally the electrical conductivity test fails to detect $33 \%$ of added water because the genuine milk has a conductivity value greater than $210 \times 10^{-5} \mathrm{ohm}^{-1} \mathrm{~cm}^{-1}$. This, however, is a relatively rare occurrence because such milk is usually obtained from women with inadequate lactation and they would therefore not be donors to a milk bank.

By using the electrical conductivity test it is possible to detect human milk which has been adulterated with cow's milk. It has been shown that the addition of cow's milk raises the conductivity of human milk, and that it is most unusual for the electrical conductivity of milk obtained from women lactating adequately in the second to fifth month of lactation to exceed $210 \times 10^{-5} \mathrm{ohm}^{-1} \mathrm{~cm}^{-1}$. If, therefore, a value greater than this is obtained, the possibility of inadequate lactation and of adulteration of the milk must be considered. To obtain a conductivity value greater than $210 \times 10^{-5} \mathrm{ohm}^{-1} \mathrm{~cm}^{-1}$ as much as $23 \%$ of cow's milk may require to be added to human milk (Miller, 1949). To prove, however, that the increased conductivity value was due to adulteration of the human milk with cow's milk rather than to inadequate lactation would entail further investigation and probably involve testweighing the mother's infant over a period of 24 hours.

\section{Comments}

The practical value of the depression of the freezing point as a test for the adulteration of women's milk with water depends not only on the ease with which it is estimated, but also on the accuracy of the result and to possible variations arising from mother to mother and the stage of lactation. Unfortunately previous research on this subject (Winter, 1896; Winter and Parmentier, 1904; Wardlaw and Dart, 1926) has been made with different types of apparatus (e.g. Beckman's thermometer) and technical procedures which influence the freezing point of a given milk sample. These results are not strictly comparable with those obtained in the present investigation and no conclusions can be drawn as to the accuracy of the results. It has been stated, however, by Wardlaw and Dart (1926) that the individual values in their series varied from -0.545 to $-0.622^{\circ} \mathrm{C}$. This is a greater variation than that of -0.531 to $0.586^{\circ} \mathrm{C}$. obtained in the present series of observations. This smaller variation increases the value of the freezing point test as a means of detecting adulteration since the amount of water which must be added to alter normal women's milk of the lowest freezing point above that of the highest normal value is less if the variation is small. Wardlaw and Dart (1926) noted a tendency for the freezing point to rise as lactation advanced, but the mean values for various stages of lactation differed very little from the mean value for all the observations. The depression of freezing point in the present series of observations was not significantly affected 
by the stage of lactation. The test, therefore, should prove equally satisfactory at whatever stage of lactation it is used. The same authors stated that milk from women aged 23 to 26 had values which on the average were slightly higher than that for younger or older women. It is unlikely that the difference between the two groups of women is significant.

Before any definite statement as to the value of the test as a means of detecting adulteration of human milk with water is made a further series of observations made by the same method is desirable. It appears, however, that the test is sensitive and the technique easy and not too time consuming. It would appear equally sensitive at whatever stage of lactation it is performed and not markedly affected by the variations normally found in milk of apparently healthy mothers. The only other test used for the detection of water added to human milk which has comparable sensitivity is the refractometric test. This test, however, requires two specimens from the woman under investigation, one of which must be known to be unadulterated. This latter sample may not be easily obtained. The fact that the freezing point test is a quantitative one and can be done with one sample of milk means that it is preferable to the refractometric test.

The electrical conductivity test as a detector of added water to human milk is probably as efficient as most tests used for this purpose, but it is only suitable for detecting $33 \%$ or more of added water to milk obtained from a woman who has passed her puerperium and is lactating adequately. The test is, however, more rapidly and easily performed than either the specific gravity test or the chloride-lactose test, both of which detect similar degrees of adulteration. The refractometric test is possibly more efficient but more time consuming.

The electrical conductivity test is of little practical value for the detection of human milk to which cow's milk has been added. This is because it may give false positive results and to eliminate the possible error would involve much work. Many other tests for adulteration with cow's milk also give unreliable results. The precipitation test, however, is reliable and most satisfactory. It is capable of detecting $2 \%$ of adulteration. The refractometric test is another reliable test but only for the detection of $20 \%$ or more of added cow's milk.

The most accurate method of investigating the possible adulteration of women's milk would appear to be the testing of the milk for acidity along the lines advocated by Soxhlet-Henkel (SH). Samples with an acidity not greater than 2 degrees (SH) are regarded as fresh. The freezing point of these samples should be estimated to detect adulteration with water. Samples with an acidity exceeding 2 degrees (SH) are either sour or contain cow's milk. These should be subjected to the precipitation test. Application of the freezing point test to samples of milk with an acidity greater than 2 degrees (SH) requires further investigation.

\section{Summary}

The depression of freezing point of human milk has been investigated. Estimations have been made on 260 samples of milk taken from 215 apparently healthy women between the fourth day to the sixth month of lactation. The results showed that the depression of freezing point ranged from 0.531 to $0.586^{\circ} \mathrm{C}$. The mean value for all the observations was $0.564^{\circ} \mathrm{C}$. The freezing point for samples taken from the two breasts frequently differed, as did the freezing point for samples taken at different times from the same woman. The mean values for samples taken from women at various stages of lactation did not differ appreciably and certainly did not suggest that the freezing point of milk tended either to rise or fall as lactation progressed.

There was no relationship between the depression of freezing point of women's milk and the chloride content or the electrical conductivity of the milk.

It has been shown that it is possible to detect the addition of $10 \%$ or more of water to human milk by using the freezing point test. From the result it is also possible to state the approximate degree of adulteration. The reliability of these conclusions depends upon the milk being fresh.

The use of the electrical conductivity test to detect adulteration of human milk with either water or cow's milk has been described. The test is recommended for the investigation of possible adulteration with water should both the freezing point and the refractometric tests be impracticable. The electrical conductivity test does not appear to be of practical value for the detection of adulteration of human milk with cow's milk, there being at least three more suitable tests for this purpose.

A scheme for testing human milk involving the freezing test and precipitation test along with a quantitative estimation of acidity has been suggested.

We wish to express our thanks to Dr. A. Comrie, of the Agricultural College, Edinburgh, for his advice on how to measure the depression of freezing point of milk. We are also grateful to the nursing staff of the Simpson Memorial Maternity Pavilion, Royal Infirmary, Edinburgh, for their assistance in collecting many of the milk samples, and to the Board of Management, Edinburgh Central Hospitals, for a grant to cover the cost of the apparatus. 
Rererences

Aschaffenburg, R. and King J. (1951). Amoiyst, 76,2

Ascociation of Official Agricultural Chemists (1930). Official and Tentative Methods of Analysis, 3rd edit. Washington, D.C.

Brakhage, G. and Raettig H. (1940). Z. Kinderheilk., 61, 654.

Bauer, J. (1913). Bbid., 11, 474. Cited by Smith, 1942

Edekstein, F. (1921). Ibid., 30, 326.

Eksdon, G. D. and Walker, G. H. ed. (1942). Richmond's Dairy Chemistry, 4th edit. D. 113, 253. London.

Gnosspelius, A. (1940). Archives of Disease in Childhood, 15, 171.

Griebel, C. (1937). Chem. Abstr., 31, 1896.

Hortvet, J. (1921). J. Ind. Eng. C hem., 13, 198.

Kappelike, G. and Gottfried, A. (1920). Münch. med. Wschr., 67, 813.

Kavser, M. E. (1935). Ibid., 821447.

(1938). Lait., 18, 805.

Keller, A. and Mai, H. (1930). Schweiz. med. Wschr., 11, 487.

Kermack, W. O. and Miller, R. A. (1951). Archives of Disease in Childhood, 26, 265.

Lyons, J. and O'Shea, M. J. (1950). Commercial Methods of Testing Milk and Milk Products, p. 140, 142. Cork University Press, and Oxford.

Mackintosh, J. M. (1947). Brit. med. Bull., 5, 1111.
Miller, R. A (1949). Some Aspects of Milk Synthesis and Compositiou in Relationship to the Mother's Ability to Breast-Feed her Infant. Ph.D. Thesis, University of Edinburgh.

Moro E (1912), Archives of Disease in Child 59ood, 26, (1913). Abstracted in Chem. Abstr., 7,846.

Moruzi, G. and Tanzi, B. (1931). Ateneo parmense, 3, 353; (1932) Abstracted in Physiol. Abstr., 16, 705.

Patterson, J. (1928). Biocherm. J., 22 758.

Rodkey, F. L. and Ball, E. G. (1946). J. Lab. clin. Med., 31, 354.

Smith. C. A. (1942). J. Pediat., $20,616$.

Solk, A. (1935) Mschr. Kinderheilk. 63, 383. Cited by Smith, 1942.

Ström. J. (1939). Nord. Med., 2 1938.

Wardlaw, H. S. H. and Dart, E. E. P. (1926). Aust. J. exp. Biol. med. Sci., 3, 129.

Winter, J. (1896). J. ber. Fortschr. Tierchem., 26, 294. and Parmentier, E (1904). Rev. gén. Lait., 3, 193. Cited by Hammarsten, p. 523. (1922)

Umikoff, N. (1896). $J$ b. Kinderheilk., 42,356

Urbach, H. (1938). Klin. Wschr., 17, 633. (1938) Abstracted in Chem. Abstr., 32, 6281 .

Zaribnicky, F. (1942). Z. Kinderheilk., 63, 543. 